\section{Requirements for submission of manuscripts}

\section{DeAr Sirs}

In comparison to other journals, requirements for submission of manuscripts to the British Journal of Psychiatry and Psychiatric Bulletin are sparse. The single page of instructions for submissions to the Brtish Journal of Psychiatry $(158,591)$ concerns style and format. In contrast, the $B M J$ provides four pages of requirements for submissions to those journals adopting the 'Vancouver style' (BMJ 1991, 302, 338-341). This includes details of the qualifications for authorship and the responsibility of authors for content and veracity. All authors are required to sign a covering letter acknowledging compliance with the requirements.

The recent paper 'Careers in psychiatric specialities 7. Substance Misuse' (Black et al, 1991) provides an example of how things may go wrong under the present system. I essentially wrote the whole article and would have therefore expected to be the sole (or certainly first) author. More importantly, I wrote the article in draft form, requesting amendments from the other authors. The draft article was submitted for publication unchanged and without my having any opportunity for correction or revision. Further anomalies included my title and place of work being incorrect.

I have previously been in a similarly invidious position when writing to the editor of another psychiatric journal requesting the return of a manuscript submitted without approval from the three senior authors. If I, an author of modest output, have twice been affected in this way, how many more have had their work hi-jacked in such a fashion and how many journals have published in good faith an inferior product? Has the time not come for the British Journal of Psychiatry and Psychiatric Bulletin to institute more detailed requirements for publication and to insist on the signature of each author acknowledging responsibility?

Regional Drug Dependence Unit

JOHN MERRILI

Prestwich Hospital

Manchester M25 7BL

\section{References}

BlaCk, D., Guthrie, E. \& MerRILl, J. (1991) Careers in psychiatric specialities 7. Substance Misuse. Psychiatric Bulletin, 15, 276-277.

DeAr SIRS

We are loathe to enter an unseemly dispute about a practical article but are so astounded by Dr Merrill's comments that we feel bound to respond.
We conceived the idea for the series of articles about careers in psychiatric specialities after arranging a training workshop for senior registrars at which it became apparent that this sort of information would be useful.

For each of the nine articles we wrote a draft and then asked a recognised expert in the speciality to add comments and suggest any modifications. This procedure was followed in each of the articles including that written with Dr Merrill. Thus, we wrote the draft, sent it to Dr Merrill, asking him to collaborate with us and comment on and modify the article as he considered appropriate. We found his modifications helpful and sent off this amended article, without further alteration, to the Bulletin. Dr Merrill's letter implies that he thought up the idea, and that he wrote the article asking us to comment on it. This is entirely misleading and inaccurate.

All the other eight collaborative authors in this series were entirely happy with the articles: indeed, one or two expressed surprise that we wished to include their names as they regarded their contributions as being of such a minor nature.

We are, therefore, at a loss as to why Dr Merrill has been so upset.

\section{Hope Hospital \\ Eccles Old Road \\ Salford M6 8HD}

DAWN BlaCk

Department of Psychotherapy

ELSE GUTHRIE

Gaskell House

Swinton Grove

Manchester M13 OEU

\section{Editorial note}

The instructions to authors have been amended (see inside front cover, this month's issue).

\section{Legal aid for representation at Mental Health Review Tribunals}

DeAr Sirs

Dr A. West's views on financial assistance to patients applying to the Mental Health Review Tribunal (Psychiatric Bulletin, June 1991, 15, 372) invite detailed comment, not only as to their inaccuracy.

The Mental Health Review Tribunal and the right to legal representation before it date from the 1959 Act not from the changes made in the early 1980s. However, the absence of legal aid meant that, for most patients, these rights were illusory. For restricted patients the position was made even worse by the tribunal not even possessing any power of diacharge.

The Mental Health (Amendment) Act 1982 changes expanding the powers of the tribunal and the 